\title{
Comparison of Critical Speeds of a Rotor System with Different Types of Finite Elements
}

\author{
Hui Ma ${ }^{a}$, Hao Zuo ${ }^{b}$, Xingyu Tai ${ }^{\mathrm{c}}$ and Bangchun Wen ${ }^{\mathrm{d}}$ \\ School of Mechanical Engineering \& Automation, Northeastern University, Shenyang 110819, China \\ ahuima@me.neu.edu.cn, bzuohao123@sina.com, ctaixingyu@126.com, dbcwen1930@vip.sina.com
}

\section{Keywords: Critical speed, Finite element, Rotor system, Modal analysis}

\begin{abstract}
The critical speeds of all kinds of high-speed rotors must be calculated in project so that all rotors can work in the safe range of speeds and avoid resonance. A single-span-two-disc rotor system is investigated by using finite element method based on ANSYS. Natural frequencies are calculated by using beam, solid, mass, shell, beam-solid, beam-shell elements and critical speeds are obtained from Campbell diagram. Finally, the first and second critical speeds are measured by a test rig. Comparison of theoretical and experimental results is performed to assess the accuracy of different element combining forms.
\end{abstract}

\section{Introduction}

In project, high-speed rotary machinery working near the critical speed will cause violent vibration while many rotating machineries work over the first critical speed, so critical speed must be considered as an important parameter in rotary machinery design. Critical speed by the theoretical analysis has been developed using various analytical methods. However, it is not only complicated to use the analytical method for some complicated rotors but also difficult to calculate the critical speed more than the second-order. And various factors will affect the result which will reduce the calculation accuracy. It is feasible for some simple rotors to use the experimental method, but test condition can't meet most complicated rotors and test cost is very expensive. Finite element method can effectively solve the problems mentioned above and solve the critical speed of rotors with complex structure. Based on large-scale finite element software ANSYS, the natural frequencies of rotor system and its corresponding critical speeds can be obtained.

In this paper, a single span rotor system with two discs is researched by using a variety of element forms such as beam, solid, mass, shell which are provided by ANSYS. The critical speeds by different element combining forms are obtained and compared with experimental results to verify the accuracy of the simulation results. The advantages and disadvantages by using various elements are also compared in the calculation of critical speed.

\section{Mechanical model of rotor-bearing system}

In this paper, the research object is a single span rotor system with two discs, as is shown in Fig. 1. The test rig mainly consists of motor, elastic coupling, shaft, rotating disc, graphite bearing and sliding bearing. In order to establish a better finite element model, some simplifications are introduced as follows: (1) The bearings are linearized ideally with stiffness and damping; (2) The supports and/or foundations are rigid; (3) The torsional movements are negligible. In ANSYS, beam 188 and solid186 can be used to simulate the shaft and shaft coupling and beam188, solid186, mass 21 and shell281 can be used to simulate rotating disc. The finite element model of the rotor system can be established based on different element combinations, as are shown in Table 1.

The finite element model of rotor-bearing is established by using the first combination, as is shown in Fig. 2. In the figure, the black dots represent the node and the number represents node number. The detailed model parameters are shown in Table 2 . The density of shaft coupling, shaft and rotating disc is $7.85 \times 10^{3} \mathrm{~kg} / \mathrm{m}^{3}$, elastic modulus is $210 \mathrm{GPa}$, Poisson's ratio is 0.3 . 


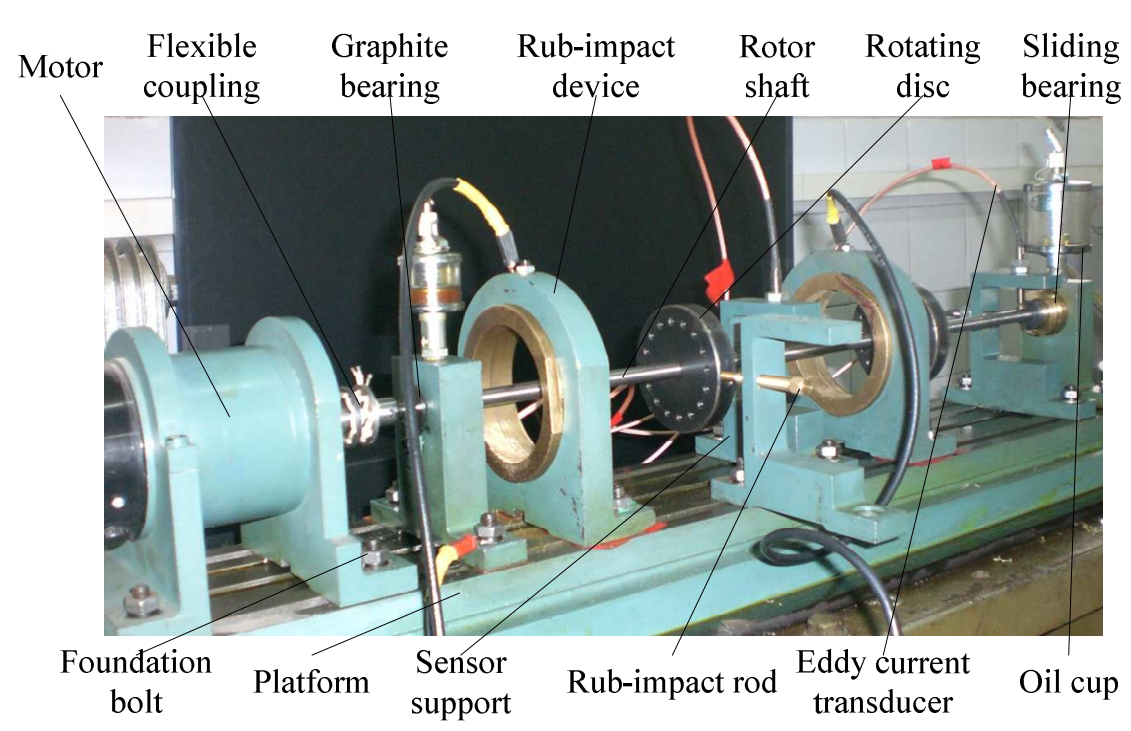

Fig. 1 Set-up diagram of rotor test rig

Table 1 Different element combining forms to simulate the rotor-bearing system

\begin{tabular}{cccccc}
\hline \multicolumn{2}{c}{ Simulation objects } & Coupling & Shaft & Rotating disc & Bearing \\
\hline & Combining form 1 & beam188 & beam188 & beam188 & combi214 \\
Different element & Combining form 2 & solid186 & solid186 & solid186 & combi214 \\
combining forms & Combining form 3 & beam188 & beam188 & mass21 & combi214 \\
& Combining form 4 & beam188 & beam188 & solid186 & combi214 \\
& Combining form 5 & beam188 & beam188 & shell281 & combi214 \\
\hline
\end{tabular}

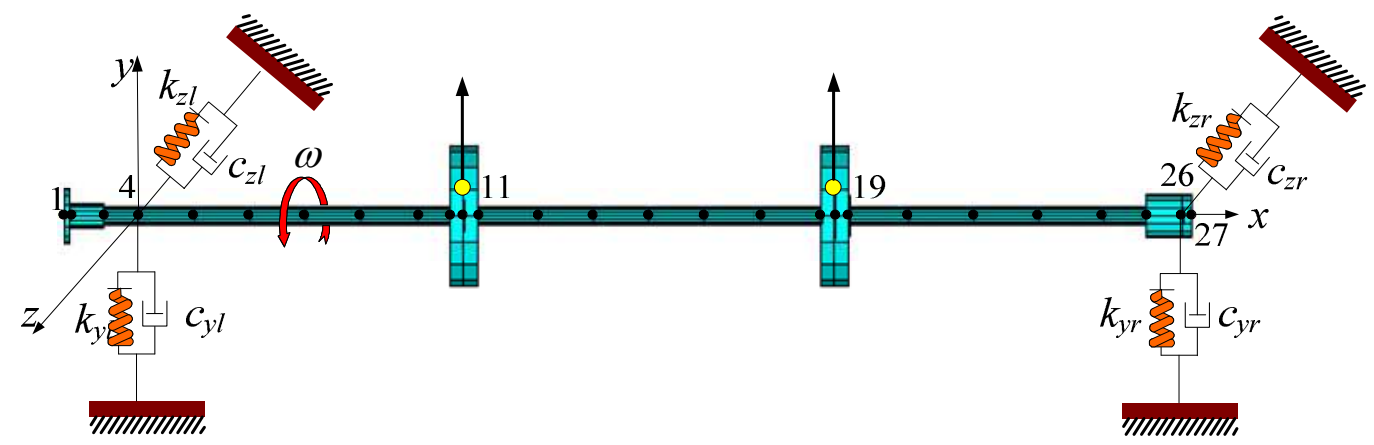

Fig. 2 Finite element model of rotor-bearing system

\section{Modal analysis of rotor-bearing system}

Any structure or component has natural frequencies and corresponding modal shapes which belong inherent characteristics of structure or component. Modal analysis is used to determine natural frequency and modal shape of the structure, namely, the eigenvalues and eigenvectors of characteristic equation. The motion differential equations for the rotor system can be expressed as follows

$$
\boldsymbol{M} \ddot{\boldsymbol{u}}+(\boldsymbol{C}+\boldsymbol{G}) \dot{\boldsymbol{u}}+\boldsymbol{K} \boldsymbol{u}=\boldsymbol{Q}
$$

Where $\boldsymbol{M}, \boldsymbol{C}, \boldsymbol{G}, \boldsymbol{K}$ are the mass matrix, damping matrix, gyroscopic matrix and stiffness matrix of rotor system, respectively; $\boldsymbol{Q}$ is the generalized force vector acts on the rotor system; $\boldsymbol{u}, \dot{\boldsymbol{u}}, \ddot{\boldsymbol{u}}$ are the node displacement vector, velocity vector and acceleration vector, respectively.

To solve the vibration modal of rotors and let $\boldsymbol{Q}=0$, Eq. (1) becomes a homogeneous second-order differential equations

$$
\boldsymbol{M} \ddot{\boldsymbol{u}}+(\boldsymbol{C}+\boldsymbol{G}) \dot{\boldsymbol{u}}+\boldsymbol{K u}=0
$$

The solutions of the equations are

$$
\boldsymbol{u}=\boldsymbol{u}_{0} e^{(\lambda+\mathrm{i} \omega t)}=\boldsymbol{u}_{0} e^{\lambda} e^{\mathrm{i} \omega t}
$$


Where $\boldsymbol{u}_{0}$ is initial displacement; $\lambda+\mathrm{i} \omega$ is eigenvalue, there $\lambda$ is damped exponential, $\mathrm{i}$ is imaginary unit; $\omega$ is the damped natural frequency. The relationship $\omega$ with the critical speed is $n_{c}=60 \omega(\mathrm{r} / \mathrm{min}), \boldsymbol{u}_{0} e^{\lambda t}$ indicates that amplitude changes with time, and $e^{\mathrm{i} \omega t}$ is a periodic variation. Substitute the Eq. (3) into Eq. (4) and the final equation is as follows

$$
\boldsymbol{M}(\lambda+\mathrm{i} \omega)^{2}+(\boldsymbol{C}+\boldsymbol{G})(\lambda+\mathrm{i} \omega)+\boldsymbol{K}=0
$$

The eigenvalues and corresponding modes can be obtained by solving Eq. (4). In this paper, QR damped method is selected to calculate eigenvalues in order to consider the effect of bearing damping in the ANSYS modal analysis.

Table 2 Model parameters of the rotor-bearing system

\begin{tabular}{|c|c|c|c|c|c|}
\hline Node number & $\begin{array}{l}\text { Axial position } \\
(\mathrm{mm})\end{array}$ & $\begin{array}{l}\text { Bearings/Rotating } \\
\text { discs } \\
\end{array}$ & $\begin{array}{l}\text { Element } \\
\text { number }\end{array}$ & Length (mm) & Diameter $(\mathrm{mm})$ \\
\hline 1 & 0 & & 1 & 3 & 32 \\
\hline 2 & 3 & & 2 & 18 & 14 \\
\hline 3 & 21 & & 3 & 19 & 10 \\
\hline 4 & 40 & Left bearing & 4 & 30 & 10 \\
\hline 5 & 70 & & 5 & 30 & 10 \\
\hline 6 & 100 & & 6 & 30 & 10 \\
\hline 7 & 130 & & 7 & 30 & 10 \\
\hline 8 & 160 & & 8 & 30 & 10 \\
\hline 9 & 190 & & 9 & 17.5 & 10 \\
\hline 10 & 207.5 & & 10 & 7.5 & 80 \\
\hline 11 & 215 & Rotating disc 1 & 11 & 7.5 & 80 \\
\hline 12 & 222.5 & & 12 & 32.5 & 10 \\
\hline 13 & 255 & & 13 & 30 & 10 \\
\hline 14 & 285 & & 14 & 30 & 10 \\
\hline 15 & 315 & & 15 & 30 & 10 \\
\hline 16 & 345 & & 16 & 30 & 10 \\
\hline 17 & 375 & & 17 & 32.5 & 10 \\
\hline 18 & 407.5 & & 18 & 7.5 & 80 \\
\hline 19 & 415 & Rotating disc 2 & 19 & 7.5 & 80 \\
\hline 20 & 422.5 & & 20 & 32.5 & 10 \\
\hline 21 & 455 & & 21 & 35 & 10 \\
\hline 22 & 490 & & 22 & 35 & 10 \\
\hline 23 & 525 & & 23 & 35 & 10 \\
\hline 24 & 560 & & 24 & 22.5 & 10 \\
\hline 25 & 582.5 & & 25 & 20 & 25 \\
\hline 26 & 602.5 & Right bearing & 26 & 5 & 25 \\
\hline 27 & 607.5 & & & & \\
\hline \multirow{2}{*}{ Left bearing } & $k_{z l}(\mathrm{~N} / \mathrm{m})$ & $k_{y l}(\mathrm{~N} / \mathrm{m})$ & $c_{z l}(\mathrm{~N} \cdot \mathrm{s} / \mathrm{m})$ & $c_{y l}(\mathrm{~N} \cdot \mathrm{s} / \mathrm{m})$ & \\
\hline & $2 \times 10^{5}$ & $2 \times 10^{5}$ & 0 & 0 & \\
\hline \multirow{2}{*}{ Right bearing } & $k_{z r}(\mathrm{~N} / \mathrm{m})$ & $k_{y r}(\mathrm{~N} / \mathrm{m})$ & $c_{z r}(\mathrm{~N} \cdot \mathrm{s} / \mathrm{m})$ & $c_{y r}(\mathrm{~N} \cdot \mathrm{s} / \mathrm{m})$ & \\
\hline & $2 \times 10^{8}$ & $5 \times 10^{8}$ & 0 & 0 & \\
\hline
\end{tabular}

\section{Calculation of rotor-bearing system critical speed}

The critical speeds of rotor-bearing system are calculated with different element combining forms, as is shown in Table 1. Considering the effect of gyroscopic moment, the critical speeds can be determined by using Campbell diagrams, as are shown in Fig. 3. In the figure, 1X represents unbalanced exciting force, $f_{n}(n=1,2 \ldots 5)$ represents the $n$th natural frequency . By calculating natural frequencies at different rotating speeds, the 1 5 order natural frequencies are plotted. The every order natural frequency has two forms: the smaller is the backward whirl natural frequency and the larger is the forward whirl natural frequency, as are shown in Fig. 3. The critical speeds corresponding forward and backward whirl can be obtained by using the intersection of $1 \mathrm{X}$ curve and various order forward and backward natural frequencies. 


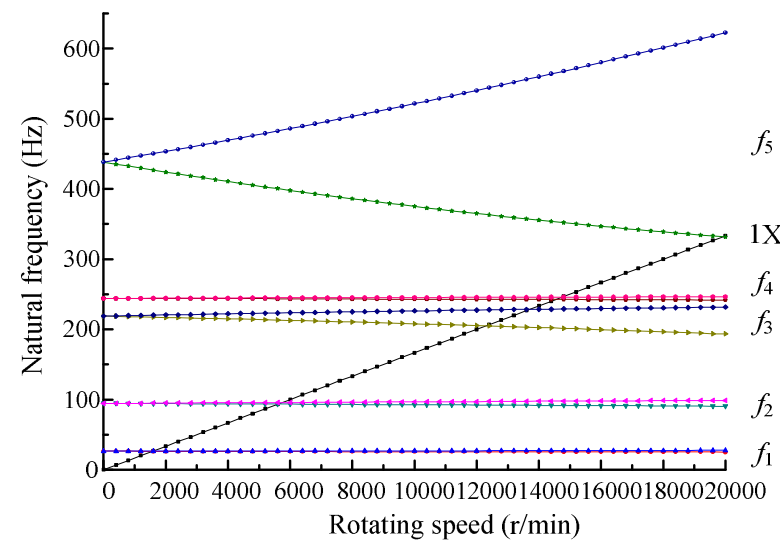

(a) Combining form 1

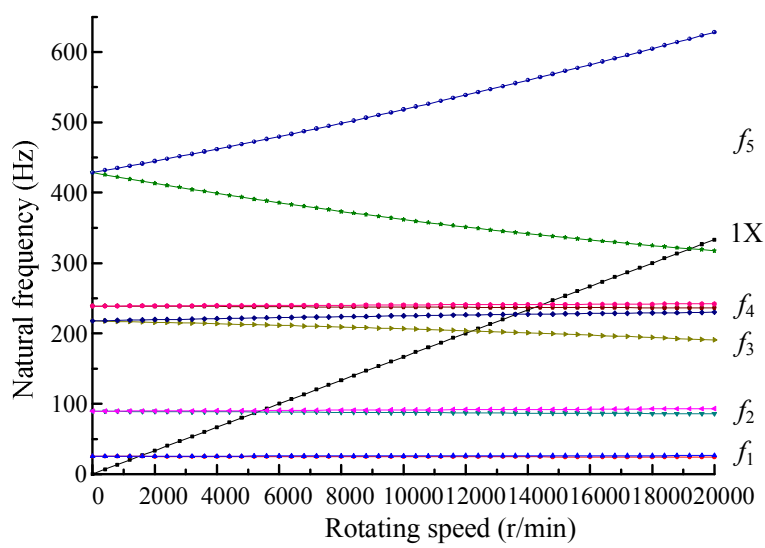

(c) Combining form 3

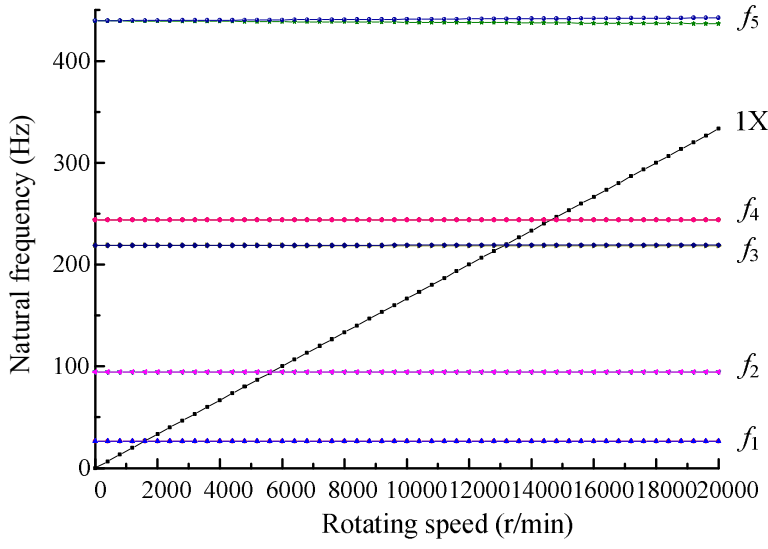

(b) Combining form 2

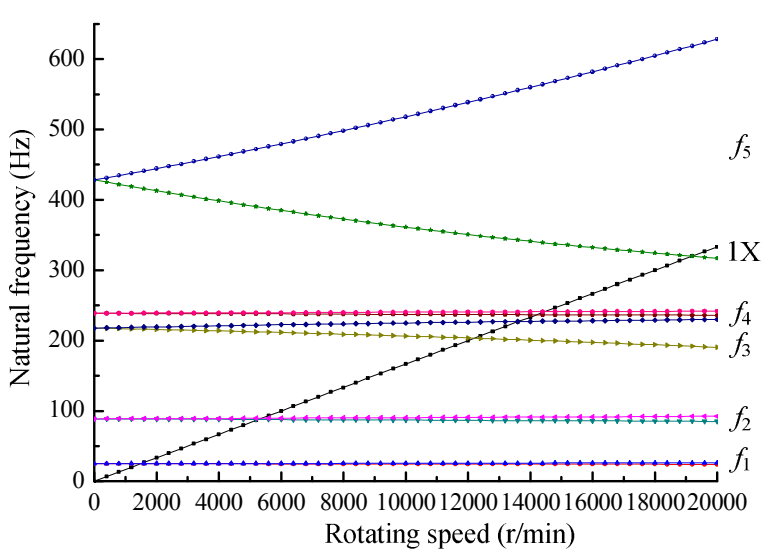

(d) Combining form 4

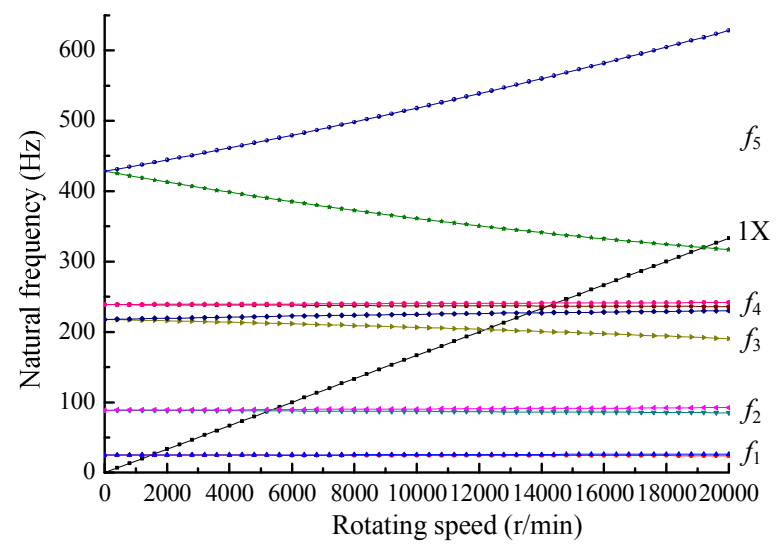

(e) Combining form 5

Fig. 3 Campbell diagram from a model analysis for different element combining forms

In ANSYS modal analysis module, by using QR damped method and Campbell diagrams, the first order BW (backward whirl critical speed) of system can be determined about $26.271 \mathrm{~Hz}(1576 \mathrm{r} / \mathrm{min})$, the first order FW (forward whirl critical speed) about $26.464 \mathrm{~Hz}(1588 \mathrm{r} / \mathrm{min}$ ), the second order BW about $93.394 \mathrm{~Hz}(5604 \mathrm{r} / \mathrm{min})$, and the second order FW about $95.744 \mathrm{~Hz}(5746 \mathrm{r} / \mathrm{min})$. Other combining forms are calculated in the same way and the first forth order forward and backward whirl critical speeds are obtained in Table 3.

The calculated results show that the calculated critical speeds by combining form 1 and 2 are very close, and so are combining form 3, 4 and 5. The difference of calculation results based on combining form 1, 2 and based on combining form 3, 4, 5 is mainly reflected in the second order FW and BW. The difference reason is mainly due to different stiffness matrix for different combining forms. By comparing Campbell diagrams of different kinds of elements in Fig. 3, the difference of BW and FW 
is small in Fig. 3(b), which shows the little influence of gyroscopic moment on combining form 2. The calculated critical speeds at different element combining forms are different to some extent, but their vibration modes are the same.

Table 3 Critical speeds at different element forms

\begin{tabular}{cccccccccc}
\hline $\begin{array}{c}\text { Different } \\
\text { element } \\
\text { combining } \\
\text { forms }\end{array}$ & BW & FW & BW & FW & BW & FW & BW & FW \\
\cline { 2 - 9 } & 26.271 & 26.464 & 93.394 & 95.744 & 204.968 & 228.487 & 242.565 & 245.961 \\
\hline $\begin{array}{c}\text { Combining } \\
\text { form 1 }\end{array}$ & 26.491 & 26.495 & 94.299 & 94.347 & 218.579 & 219.046 & 243.95 & 243.989 \\
$\begin{array}{c}\text { Combining } \\
\text { form 2 }\end{array}$ & 25.178 & 25.371 & 88.364 & 90.31 & 203.333 & 227.134 & 236.844 & 241.041 \\
$\begin{array}{c}\text { Combining } \\
\text { form 3 }\end{array}$ & 25.032 & 25.199 & 87.805 & 89.713 & 203.295 & 227.026 & 236.776 & 241.075 \\
$\begin{array}{c}\text { Combining } \\
\text { form 4 }\end{array}$ & 25.186 & 25.375 & 88.366 & 90.261 & 203.179 & 227.373 & 236.82 & 241.127 \\
$\begin{array}{c}\text { Combining } \\
\text { form 5 }\end{array}$ & & & & & & & &
\end{tabular}

\section{Comparison of experimental and simulation results}

Spectrum cascade in the process of run-up and run-down can be seen in Fig. 4. In the speeding up process, there are two order critical speeds. Because the rotor passes through the critical speeds quickly, only critical speed regions can be obtained. The first and second order critical speed regions are $26.41 \mathrm{~Hz} \sim 27.34 \mathrm{~Hz}$ and $93.38 \mathrm{~Hz} \sim 95.26 \mathrm{~Hz}$, respectively. Comparing theoretical and simulation results, it can be seen that the experimental results agree well with the calculated results of combining form 1 and 2.

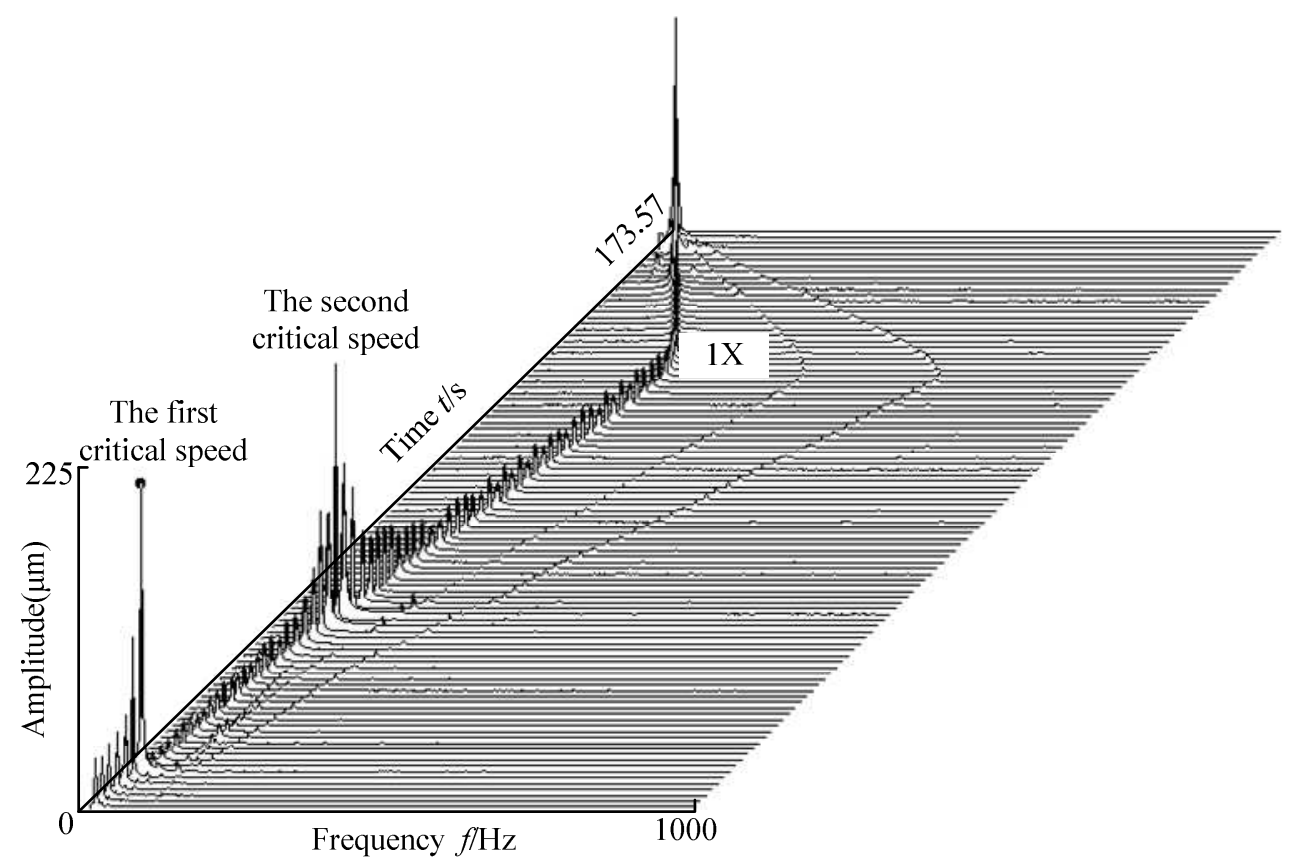

Fig. 5 Spectrum cascade in the process of run-up and run-down

\section{Conclusion}

In this paper, modal analysis is performed for a rotor-bearing system of test rig by using different element combining forms. Considering the effect of gyroscopic moment, the critical speeds can be determined by using Campbell diagram, and finally verified using experiment result. The results 
show that the simulation results using combining form 1 and 2 are more accurately than the others and the effect of gyroscopic moment on latter is less than the former. Considering the computational efficiency of combining form 1 and 2 , the former will be preferentially selected.

\section{Acknowledgments}

We are grateful to the China Natural Science Funds (NSFC, Grant No. 50805019), the Fundamental Research Funds for the Central Universities (Grant No. N100403008) for providing financial support for this work.

\section{References}

[1] A. Muszynska. Rotor dynamics [M]. CRC Taylor \& Francis Group, New York, 2005.

[2] H. D. Nelson, J. M. Mcvaugh. The dynamics of rotor-bearing systems using finite elements, ASME Journal of Engineering for Industry. 98 (1976) 593-600.

[3] R. L. Ruhl and J. F. Booker. A finite element models for distributed parameter turborotor systems. ASME Journal of Engineering for Industry. 94 (1972) 126-132.

[4] E. S. Zorzi and H. D. Nelson. Finite element simulation of rotor-bearing systems with internal damping. ASME Journal of Engineering for Power. 99 (1977) 71-76.

[5] H. D. Nelson. A Finite rotating shaft element using Timoshenko beam theory. ASME Journal of Mechanical Design.102 (1980) 793-803.

[6] F. Oncescu, etc. Investigation of the stability and steady state response of asymmetric rotors using finite element formulation. Journal of Sound and Vibration. 245 (2001) 303-328.

[7] H. Roya, J. K. Duttb, P. K. Datta. Dynamics of a viscoelastic rotor shaft using augmenting thermodynamic fields - A finite element approach. International Journal of Mechanical Sciences 50 (2008) 845-853.

[8] J. N. Hu, W. Jiang, et al. Optimal selection for stage number of high pressure multi-stage pump for $10 \mathrm{k}$ ton-scale reverse osmosis desalination systems. Journal of Drainage and Irrigation Machinery Engineering. 28 (2010) 43-46 (in Chinese).

[9] M. Chen, Y. H. Ma, et al. Rotor dynamic analysis of whole aero-engine models. Journal of Beijing university of Aeronautics and Astronautics. 33 (2007) 1013-1016 (in Chinese). 